\title{
Expression of Twist, Slug and Snail in esophageal squamous cell carcinoma and their prognostic significance
}

\author{
SHANSHAN XU ${ }^{1 *}$, YAXING ZHOU $^{1 *}$, HADETI BIEKEMITOUFU $^{1}$, HUI WANG $^{1}$, \\ $\mathrm{CHAO} \mathrm{LI}^{2}$, WENJING ZHANG ${ }^{1}$ and YUQING MA ${ }^{1}$ \\ Departments of ${ }^{1}$ Pathology and ${ }^{2}$ Respiratory Intensive Care Unit, The First Affiliated Hospital, \\ Xinjiang Medical University, Urumqi, Xinjiang 830054, P.R. China
}

Received June 18, 2020; Accepted December 8, 2020

DOI: 10.3892/ol.2021.12445

\begin{abstract}
Esophageal cancer is one of the most common types of malignancy worldwide. At present, surgical resection is the main treatment for esophageal cancer, but recurrence and distant metastasis are the main causes of mortality. The transcription factors Twist, Slug and Snail regulate epithelial-mesenchymal transition and thereby participate in tumor invasion and metastasis. The aim of the present study was to investigate the expression of Twist, Slug and Snail in esophageal squamous cell carcinoma (ESCC) and their prognostic significance. The expression of Twist, Slug and Snail in 229 paraffin-embedded ESCC and matched normal mucosal tissues was detected by immunohistochemistry. The expression differences of Twist, Slug and Snail in the ESCC and normal tissues were compared by $\chi^{2}$ test, and the associations between the three proteins and the clinicopathological parameters of ESCC were analyzed. The expression levels of Twist, Slug and Snail in 29 fresh frozen ESCC and matched normal mucosal tissues were detected by reverse transcription-quantitative PCR. The correlations among Twist, Slug and Snail in ESCC were examined by Pearson's correlation analyses. In addition, single factor and multivariate Cox regression analyses were used to analyze the influence of Twist, Slug and Snail on the prognosis of ESCC. Twist was found to be highly expressed in ESCC. The difference of Slug expression in ESCC was associated with differentiation degree, TNM stage and vascular invasion, but no significant association was observed between Snail expression and any clinicopathological parameters. In ESCC, there were significant differences in protein expression
\end{abstract}

Correspondence to: Professor Yuqing Ma, Department of Pathology, The First Affiliated Hospital, Xinjiang Medical University, 137 Luyishan South Road, Urumqi, Xinjiang 830054, P.R. China

E-mail: yuqingm0928@126.com

${ }^{*}$ Contributed equally

Key words: esophageal squamous cell carcinoma, Twist, Slug, Snail, prognosis between Twist and Snail, and Slug and Snail. The mRNA expression level of Twist in ESCC was significantly higher than that in normal esophageal mucosa. However, the mRNA expression of Slug in normal esophageal mucosa was higher than that in ESCC, and the mRNA expression levels of Twist and Snail were positively correlated in ESCC. Kaplan-Meier analysis of 229 patients with ESCC revealed that Snail influenced the overall survival, as did the co-expression of Twist and Snail. Nerve invasion was also identified as an independent factor affecting the progression-free survival of ESCC. The results indicate that Twist is highly expressed, Slug may be a tumor suppressor, and Snail is an independent prognostic factor in ESCC. Twist and Snail are positively correlated, and the simultaneous inhibition of Twist and Snail protein expression may be beneficial for prolonging the overall survival of patients with ESCC.

\section{Introduction}

Esophageal cancer is a common malignancy of the upper digestive tract, ranking 7 th and 6th for mortality and morbidity, respectively, among all types of cancer worldwide in 2018 (1). China has one of the highest incidence rates of esophageal cancer globally (1), with a crude incidence rate of 17.87/100,000 individuals (2). However, marked regional and ethnic differences exist in the distribution of esophageal cancer in China (3). Xinjiang is among the regions with the highest incidence of esophageal cancer (4), and has high morbidity and mortality rates; in particular, the Kazakh population in Xinjiang has a mortality rate of $68.88 / 100,000$, which is extremely high for this region $(5,6)$. The early symptoms of esophageal cancer are not easy to distinguish clinically and most patients are diagnosed at a late stage, while esophageal cancer is prone to metastasis at an early stage due to its extensive lymphatic drainage network (7). At present, the treatment of esophageal cancer mainly comprises surgery combined with neoadjuvant radiotherapy and chemotherapy (8). However, the 5 -year survival rate of esophageal cancer is $<20 \%$ (9), and most patients present with recurrence or metastasis following treatment. Additionally, $>90 \%$ of cases present as esophageal squamous cell carcinoma (ESCC) in Asian countries (3). Therefore, in order to develop more effective treatment methods for advanced esophageal cancer, it would be helpful 
to identify the genes associated with the occurrence and development of ESCC, clarify their mechanism of action and explore potential specific therapeutic targets.

Commonly occurring biological changes in the pathogenesis of ESCC include the activation of oncogenes, inactivation of tumor suppressor genes and changes in molecular markers associated with the etiology of ESCC (10). Research into ESCC has increasingly focused on tumor stem cells. Twist, Slug and Snail have been found to endow tumor cells with stem cell characteristics, and play important roles in epithelial-mesenchymal transition (EMT). EMT is a complex process by which epithelial cells transform into stromal cells, and is important in embryonic development, chronic inflammation, tissue reconstruction, cancer invasion and metastasis, and various fibrotic diseases. Its main manifestations are the decreased expression of cell adhesion molecules such as mucoproteins and E-cadherin, remodeling of the cytoskeleton with vimentin enrichment, and the development of interstitial cell characteristics. When EMT occurs, epithelial cells lose polarity, become disconnected from the basement membrane and acquire characteristics typical of interstitial cells, including high migration and invasion activities, resistance to apoptosis and degradation of the extracellular matrix (11). E-cadherin is a calcium-dependent transmembrane protein, which is involved in the maintenance of cell integrity and polarity; the loss of its expression results in reduced cell adhesion and increased invasiveness (12). Classical EMT transcription factors, including Twist, Slug and Snail, are able to downregulate the expression of E-cadherin and induce EMT, thereby promoting the invasiveness of tumors (13).

Twist is a transcription factor with a basic helix-loop-helix protein structure (14). It plays an important role in the development of the embryo, and also induces mesenchymal markers during tumor progression and participates in the EMT of certain epithelium-derived tumor cells. The underlying mechanism involves the binding of Twist to the E-box element in the promoter region of the E-cadherin gene, which inhibits the activity of the promoter and leads to a reduction in the transcription of E-cadherin; this then induces EMT, which increases the migration, invasion and metastasis of tumor cells $(15,16)$. Twist is known to play a role in a variety of invasive cancers, including breast (17), lung (18) and prostate cancer (19).

Snail and Slug are members of the Snail family, which consists of three members: Snail, Slug (Snail2) and Snail3. The Snail family members are similar in structure, each comprising a carboxyl end with a $\mathrm{C}_{2} \mathrm{H}_{2}$ zinc finger structure (20). These conserved zinc finger sequences are composed of two $\beta$-folds and an $\alpha$-helix. A specific sequence of the zinc finger can combine with the E-box CACGTG sequence in the promoter region of a downstream target gene so as to regulate the expression of the gene. As a key transcriptional inhibitor of E-cadherin expression in EMT, Snail plays important roles in embryonic development and tumor progression. Snail imbues tumor cells with characteristics similar to those of cancer stem cells, and promotes drug resistance, tumor recurrence and metastasis (21). In a variety of tumor types, the increased expression of Snail positively correlates with tumor metastasis, as well as drug and immune tolerance, and suggests a poor prognosis. Therefore, Snail may be therapeutically targeted for the inhibition of tumor progression $(22,23)$. Slug is a classic EMT transcription factor, which combines with promoter element (E-box) of the downstream gene E-cadherin and directly inhibits E-cadherin expression, thereby reducing cell adhesion and cell polarity (24), inducing EMT and promoting the development of tumors. Slug has been reported to be associated with various biological functions of tumors, including invasion and migration (25).

Twist, Slug and Snail may play important roles in the development of ESCC. The aim of the present study was to detect the expression of Twist, Slug and Snail in ESCC by immunohistochemistry and reverse transcription-quantitative polymerase chain reaction (RT-qPCR), analyze the associations between Twist, Slug and Snail and clinicopathological parameters, and determine their impact on the prognosis of ESCC, in order to provide a scientific basis for improving the prognosis of patients with ESCC.

\section{Materials and methods}

Patients. The paraffin-embedded ESCC tissues, matched normal esophageal mucosal tissues and clinicopathological parameters of 229 cases of ESCC were collected from the Department of Pathology of the First Affiliated Hospital of Xinjiang Medical University (Xinjiang, China) between January 2014 and December 2018. Among them, 115 were of Han ethnicity and 114 were of Kazakh ethnicity. The age range of the cohort was 32-84 years (median age, 60 years). The cases were assigned to the following groups: Age $(\leq 60$ or $>60$ years), sex (male or female), ethnicity (Han or Kazak), tumor location (upper, middle or lower segment), tumor size ( $<3$ or $\geq 3 \mathrm{~cm}$ ), degree of differentiation (high, medium or low), depth of invasion (mucosal, muscular or whole layer), lymph node metastasis (yes or no), vascular invasion (yes or no), nerve invasion (yes or no); and TNM stage (I, II, III or IV). A total of 29 matched pairs of fresh frozen ESCC and normal esophageal mucosal tissues between October 2007 and December 2018 were collected the specimen bank of Xinjiang Medical University. The 229 patients with paraffin-embedded ESCC tissues were followed up by telephone and their details were included in the inpatient log. The start date of follow-up was the date when the patient was diagnosed with ESCC, and the end date was July 1,2019 . The 29 cases with fresh frozen tissues were not followed up.

Immunohistochemical staining. The 229 paraffin-embedded ESCC and normal mucosal tissues were made into tissue chips, sliced into $4-\mu \mathrm{m}$ sections, deparaffinized in xylene and rehydrated in 100, 95, 80 and 70\% ethanol. Following treatment with $3 \%$ hydrogen peroxide to block endogenous peroxidase activity, the sections were heated with citric acid (pH 6; Snail and Slug analysis) or EDTA (pH 9; Twist analysis) in boiling water at $100^{\circ} \mathrm{C}$ for antigen retrieval. The sections were then treated with goat serum (Blocking normal sheep serum; cat. no. ZLI-9022; undiluted; Beijing Zhongshan Jinqiao Biotechnology Co., Ltd.) at room temperature to block non-specific antigens for $15 \mathrm{~min}$. Subsequently, the sections were incubated with rat anti-human Twist (1:50; cat. no. ab175430; Abcam) overnight at $4^{\circ} \mathrm{C}$ for $10 \mathrm{~h}$, or rat anti-human Slug (1:100; cat. no. pb9439; Boster Biological 
Technology) and goat anti-human Snail antibodies (1:800; cat. no. ab53519; Abcam) at $37^{\circ} \mathrm{C}$ for $60 \mathrm{~min}$. Next, the tissue chips were washed with PBS and the sections were incubated with secondary antibodies (universal kit, cat. no. PV-6000, undiluted for Twist and Slug; goat two step detection kit, cat. no. PV-9003, undiluted for Snail; both kits from Beijing Zhongshan Jinqiao Biotechnology Co., Ltd.) for $30 \mathrm{~min}$ at $37^{\circ} \mathrm{C}$. The slides were subsequently stained with 3,3'-diaminobenzidine, dehydrated, sealed and observed under a light microscope (DM300; Leica Microsystems $\mathrm{GmbH}$; magnifications, x4, x10 and x20). The staining strength was scored as follows: 0, no staining; 1 , weak staining; 2, medium staining); and 3, strong staining. The percentage of positive cells was scored as follows: $0,<5 ; 1,5-25 ; 2,26-50$; and $3,>50 \%$. The staining index was calculated by multiplying the score for the percentage of positive cells by the score for staining strength. If the staining index calculation was $<6$, the expression level was defined as negative expression, otherwise, it was defined as positive expression. The final results were interpreted by two senior pathologists. If there was a difference in opinion, the results were judged by a third senior pathologist.

$R T$ - $q P C R$. The 29 fresh ESCC tissues and their matched normal mucosa tissues were stored in a refrigerator at $-80^{\circ} \mathrm{C}$. Total RNA was extracted by grinding $200 \mathrm{mg}$ tissue in a liquid nitrogen environment, adding $1 \mathrm{ml} \mathrm{TRIzol}{ }^{\circledR}$ (Invitrogen; Thermo Fisher Scientific, Inc.) and collecting the extract in a 1.5-ml Eppendorf (EP) tube. Vortex oscillation was performed for $30 \mathrm{sec}$. Following the addition of chloroform $(0.2 \mathrm{ml})$, the tube was shaken vigorously for $30 \mathrm{sec}$ and kept at room temperature for $10 \mathrm{~min}$. Centrifugation was then performed at $12,000 \mathrm{x}$ g at $4^{\circ} \mathrm{C}$ for $15 \mathrm{~min}$. The colorless aqueous upper layer $(\sim 0.5 \mathrm{ml})$ was transferred to another EP tube, combined with an equal volume of isopropanol, kept at room temperature for $10 \mathrm{~min}$, and then centrifuged at $12,000 \mathrm{x} \mathrm{g}$ and $4^{\circ} \mathrm{C}$ for $10 \mathrm{~min}$. The supernatant was discarded, $1 \mathrm{ml} 75 \%$ ethanol was added to the RNA precipitate, and the mixture was shaken prior to centrifugation at $7,500 \mathrm{x} \mathrm{g}$ and $4^{\circ} \mathrm{C}$ for $10 \mathrm{~min}$. After discarding the supernatant, the residual liquid was dried at room temperature for 5-10 $\mathrm{min}$. The purity of the resulting precipitate was determined by calculation of the ratio of optical densities at 260 and $280 \mathrm{~nm}$. RT was conducted using the RevertAid First Strand cDNA Synthesis kit (cat. no. K1622; Thermo Fisher Scientific, Inc.) at $42^{\circ} \mathrm{C}$ for $60 \mathrm{~min}$ and then $72^{\circ} \mathrm{C}$ for $5 \mathrm{~min}$. Following RT, the cDNA was stored at $-20^{\circ} \mathrm{C}$ until required for qPCR. SYBR Green dye (QuantiNova SYBR Green PCR kit; cat. no. 208054; Qiagen China Co., Ltd.) and a 7500 Real-Time PCR system (Applied Biosystems; Thermo Fisher Scientific, Inc.) were used to detect the expression of the target genes. The primers used are shown in Table I. $\beta$-actin was used as the reference gene. All reactions were carried out three times under the following conditions: Activation of the polymerase for $2 \mathrm{~min}$ at $50^{\circ} \mathrm{C}$, initial denaturation for $10 \mathrm{~min}$ at $94^{\circ} \mathrm{C}$, followed by 40 cycles of denaturation for $15 \mathrm{sec}$ at $94^{\circ} \mathrm{C}$, and annealing and elongation for $30 \mathrm{sec}$ at $60^{\circ} \mathrm{C}$. The mRNA expression of the target gene was calculated using the $2^{-\Delta \Delta \mathrm{Cq}}$ method (26).
Table I. Quantitative polymerase chain reaction primer pairs for marker molecule analysis.

\begin{tabular}{ll} 
Molecule & \multicolumn{1}{c}{ Primer sequence (5'-3') } \\
\hline Twist-F & GTCCGCAGTCTTACGAGGAG \\
Twist-R & GCTTGAGGGTCTGAATCGGGCT \\
Slug-F & GCTACCCAATGGCCTCTCTC \\
Slug-R & CTTCAATGGCATGGGGGTCT \\
Snail-F & TCGGAAGCCTAACTACAGCGA \\
Snail-R & AGATGAGCATTGGCAGCGAG \\
$\beta$-actin-F & CATGTACGTTGCTATCCAGGC \\
$\beta$-actin-R & CTCCTTAATGTCACGCACGAT
\end{tabular}

F, forward; R, reverse.

Statistical analysis. SPSS 17.0 statistical software (SPSS, Inc.) was used to analyze the associations between Twist, Snail and Slug and the clinicopathological characteristics of the patients with ESCC using $\chi^{2}$ and Fisher's exact tests. The mRNA expression levels of Twist, Snail and Slug in ESCC and adjacent tissues were compared using paired t-tests. The correlations among Twist, Snail, Slug and their combinations were analyzed by Spearman's rank and Pearson's correlation analyses. Overall and progression-free survival times were used to evaluate the prognosis of the patients. The progression-free survival time was defined as the time from the diagnosis of esophageal cancer to the time of tumor progression or death. The overall survival time was defined as the time from the diagnosis of esophageal cancer to the time of death or final follow-up (July 1, 2019). The Kaplan-Meier method (single-factor analysis) and Cox risk proportion model (multi-factor analysis) were used to analyze the survival and prognosis of the patients with ESCC. The effects of Twist, Snail and Slug protein expression and clinicopathological parameters on the prognosis of ESCC were analyzed by Kaplan-Meier analysis. Based on the results of the Kaplan-Meier analysis, the independent factors associated with the prognosis of ESCC were identified and further analyzed using the Cox proportional hazards model. $\mathrm{P}<0.05$ was considered to indicate a statistically significant result.

\section{Results}

Expression of Twist, Snail and Slug in ESCC and their association with clinicopathological parameters. Twist, Snail and Slug are important transcription factors in tumors. In ESCC, Twist is expressed in the nucleus, Snail in the cytoplasm or nucleus, and Slug in the cytoplasm (Fig. 1). In the 229 cases of ESCC, 135 tumor tissues were positive for Twist (59.0\%; Table II and Fig. 1A) and 94 were negative (41.0\%; Table II and Fig. 1B). In the normal esophageal mucosa, 36 cases (15.7\%; Table II and Fig. 1C) were positive for Twist and $193(84.3 \%)$ were negative (Table II and Fig. 1D). A total of 132 ESCC specimens were positive for Snail (57.6\%; Table II and Fig. 1E), and 97 were negative (42.4\%); 112 were positive for Slug (48.9\%; Table II and Fig. 1G), and 117 were negative (51.1\%; Table II). Twist and Snail were highly expressed in ESCC, but Slug expression was positive in $<50 \%$ 
Table II. Expression rates of Twist, Snail and Slug in ESCC and esophageal normal mucosa.

A, Twist

\begin{tabular}{lccc}
\hline & \multicolumn{3}{c}{ ESCC } \\
\cline { 2 - 4 } Mucosa & Positive $(\mathrm{n}=135)$ & Negative $(\mathrm{n}=94)$ & P-value \\
\hline Positive $(\mathrm{n}=36)$ & $32(23.7)$ & $4(4.3)$ & $<0.001$ \\
Negative $(\mathrm{n}=193)$ & $103(76.3)$ & $90(95.7)$ & 15.82 \\
\hline
\end{tabular}

B, Snail

\begin{tabular}{lccc}
\hline & \multicolumn{3}{c}{ ESCC } \\
\cline { 2 - 4 } Mucosa & Positive $(\mathrm{n}=132)$ & Negative $(\mathrm{n}=97)$ & P-value \\
\hline Positive $(\mathrm{n}=0)$ & 0 & 0 & - \\
Negative $(\mathrm{n}=229)$ & $132(57.6)$ & $97(42.4)$ & - \\
\hline
\end{tabular}

C, Slug

\begin{tabular}{lccc}
\hline & \multicolumn{3}{c}{ ESCC } \\
\cline { 2 - 4 } Mucosa & Positive $(\mathrm{n}=112)$ & Negative $(\mathrm{n}=117)$ & $\chi^{2}$ \\
\hline Positive $(\mathrm{n}=0)$ & 0 & 0 & - \\
Negative $(\mathrm{n}=229)$ & $112(48.9)$ & $117(51.1)$ & - \\
\hline
\end{tabular}

Expression frequencies are presented as n (\%). ESCC, esophageal squamous cell carcinoma.
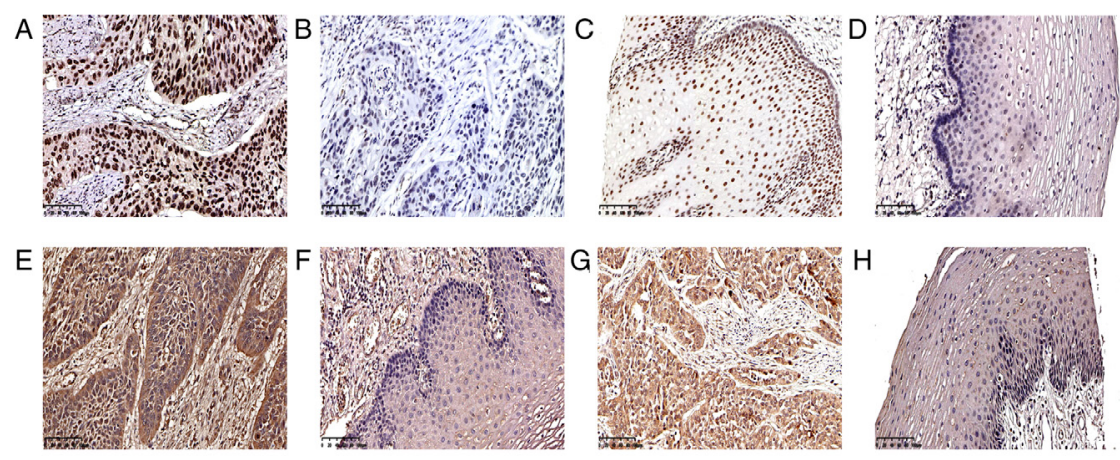

Figure 1. Immunohistochemical staining features of ESCC and normal esophageal mucosa. Distinct (A) positivity and (B) negativity of ESCC cell nuclei for Twist. Distinct (C) positivity and (D) negativity of normal esophageal mucosal cell nuclei for Twist. (E) Distinct positivity of ESCC cell cytoplasm for Snail. (F) Distinct negativity of esophageal mucosal cell cytoplasm for Snail. (G) Distinct positivity of ESCC cell cytoplasm for Slug. (H) Distinct negativity of esophageal mucosal cell cytoplasm for Slug (magnification, x200). ESCC, esophageal squamous cell carcinoma.

of the ESCC samples. The expression of Snail (Table II and Fig. 1F) and Slug (Table II and Fig. 1H) in all specimens of normal esophageal mucosa was negative, and the frequency of Twist expression in the ESCC and normal mucosal tissues was significantly different $(\mathrm{P}<0.001$; Table II).

The 229 cases of ESCC included 115 Han and 114 Kazakh individuals. The $\chi^{2}$ test was used to analyze the associations of Han and Kazakh patients with clinicopathological parameters (Table III). The results showed that there were statistically significant differences in age $(\mathrm{P}=0.05)$, tumor location $(\mathrm{P}=0.039)$ and vascular invasion between patients of different ethnicities $(\mathrm{P}=0.019)$. The proportion of Kazakh patients aged $\leq 60$ years was higher than that of Han. In Kazakh patients, ESCC was more likely to be located in the middle and lower part of the esophagus, but less likely to be associated with vascular invasion.

The $\chi^{2}$ test was used to analyze the association the expression of Twist, Snail and Slug with the clinicopathological parameters of the 229 cases of ESCC (Table IV). The results showed that the expression of Twist was associated with sex 
Table III. Characteristics of 229 patients with esophageal squamous cell carcinoma.

\begin{tabular}{|c|c|c|c|c|c|}
\hline \multirow[b]{2}{*}{ Clinicopathological parameters } & \multirow[b]{2}{*}{ No. } & \multicolumn{2}{|c|}{$\mathrm{N}(\%)$} & \multirow[b]{2}{*}{ P-value } & \multirow[b]{2}{*}{$\chi^{2}$} \\
\hline & & Han & Kazakh & & \\
\hline Total & 229 & 115 & 114 & & \\
\hline Age, years & & & & 0.050 & 7.799 \\
\hline$\leq 60$ & 84 & $32(38.1)$ & $52(61.9)$ & & \\
\hline$>60$ & 145 & $83(57.2)$ & $62(42.8)$ & & \\
\hline Sex & & & & 0.133 & 2.253 \\
\hline Male & 163 & $87(53.4)$ & $76(46.6)$ & & \\
\hline Female & 66 & $28(42.4)$ & $38(57.6)$ & & \\
\hline Tumor location & & & & 0.039 & 6.471 \\
\hline Upper & 11 & $9(81.8)$ & $2(18.2)$ & & \\
\hline Middle & 136 & $71(52.2)$ & $65(47.8)$ & & \\
\hline Lower & 82 & $35(42.7)$ & $47(57.3)$ & & \\
\hline Tumor size & & & & 0.918 & 0.011 \\
\hline$<3 \mathrm{~cm}$ & 67 & $34(50.7)$ & $33(49.3)$ & & \\
\hline$\geq 3 \mathrm{~cm}$ & 162 & $81(50.0)$ & $81(50.0)$ & & \\
\hline Differentiation & & & & 0.376 & 1.958 \\
\hline Low & 47 & $25(53.2)$ & $22(46.8)$ & & \\
\hline Medium & 123 & $65(52.8)$ & $58(47.2)$ & & \\
\hline High & 59 & $25(42.4)$ & $34(57.6)$ & & \\
\hline Depth of invasion & & & & 0.242 & 2.840 \\
\hline Mucosa & 6 & $5(83.3)$ & $1(16.7)$ & & \\
\hline Muscle & 94 & $45(47.9)$ & $49(52.1)$ & & \\
\hline Full & 129 & $65(50.4)$ & 64 (49.6) & & \\
\hline TNM stage & & & & 0.564 & 2.039 \\
\hline I & 16 & $8(50.0)$ & $8(50.0)$ & & \\
\hline II & 143 & 67 (46.9) & $76(53.1)$ & & \\
\hline III & 48 & $27(56.3)$ & $21(43.7)$ & & \\
\hline IV & 22 & $13(59.1)$ & $9(40.9)$ & & \\
\hline Lymph node metastasis & & & & 0.076 & 3.138 \\
\hline No & 152 & $70(46.1)$ & $82(53.9)$ & & \\
\hline Yes & 77 & $45(58.4)$ & $32(41.6)$ & & \\
\hline Vascular invasion & & & & 0.019 & 0.891 \\
\hline No & 186 & $93(50.0)$ & $93(50.0)$ & & \\
\hline Yes & 43 & $22(51.2)$ & $21(48.8)$ & & \\
\hline Nerve invasion & & & & 0.500 & 0.456 \\
\hline No & 179 & $92(51.4)$ & $87(48.6)$ & & \\
\hline Yes & 50 & $23(46.0)$ & $27(54.0)$ & & \\
\hline Radiotherapy or chemotherapy & & & & 0.961 & 0.002 \\
\hline No & 149 & $75(50.3)$ & $74(49.7)$ & & \\
\hline Yes & 80 & $40(50.0)$ & $40(50.0)$ & & \\
\hline
\end{tabular}

$(\mathrm{P}=0.040)$. The positive expression rate of Twist was $63.2 \%$ in male patients, which was higher than that in female patients (48.5\%). Slug was associated with the degree of differentiation $(\mathrm{P}=0.048)$, TNM stage $(\mathrm{P}=0.050)$ and vascular invasion $(\mathrm{P}=0.017)$. The positive expression rate of Slug in poorly differentiated ESCC was $44.6 \%$, in ESCC of medium differentiation was $43.9 \%$ and highly differentiated ESCC was $62.7 \%$.
This indicated Slug positivity was most frequent in cases with highly differentiated ESCC. With regards to TNM stage, the positive expression rate of Slug was $81.3 \%$ in stage I, $48.3 \%$ in stage II, $43.8 \%$ in stage III and $40.9 \%$ in stage IV, indicating that Slug positivity was most frequent in patients with ESCC at an early TNM stage. The positive expression rate of Slug in ESCC without vascular invasion was $52.7 \%$, which was 


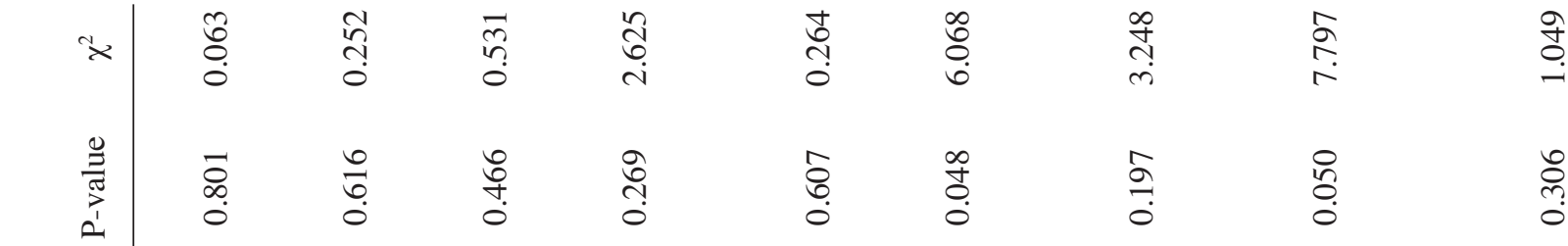

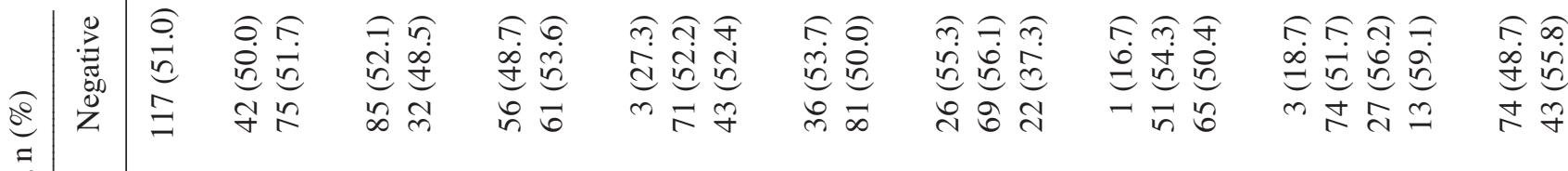

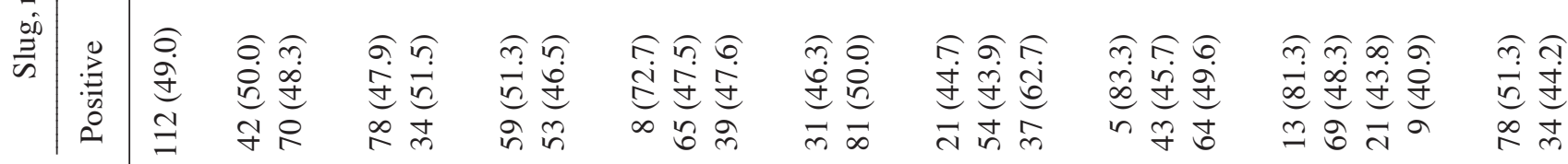

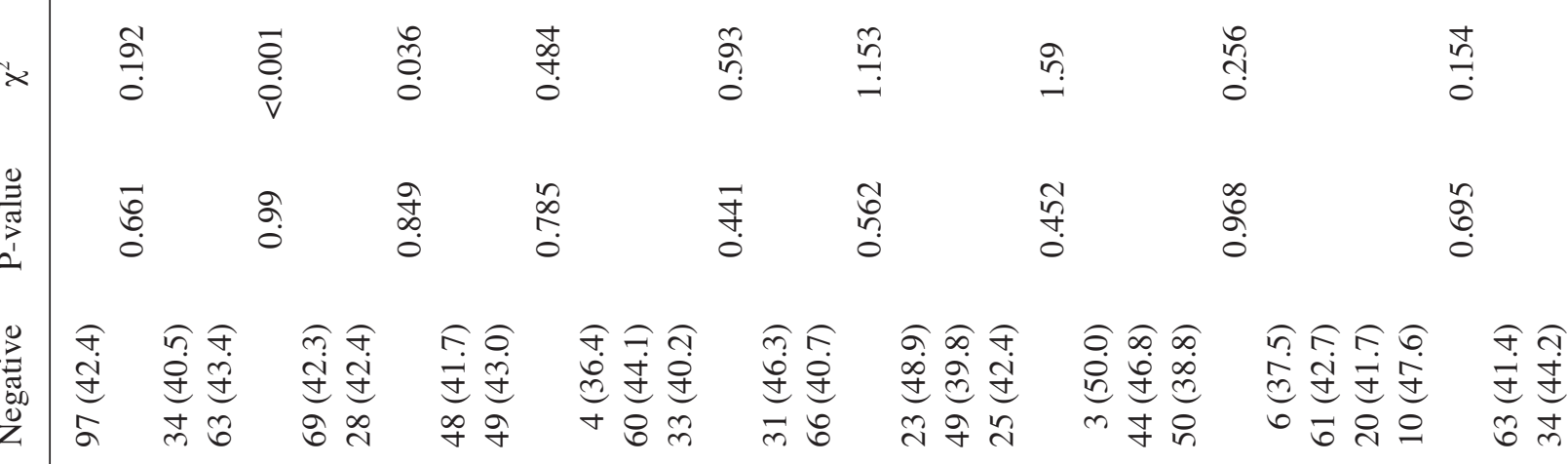

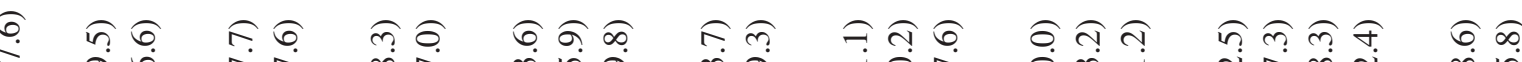

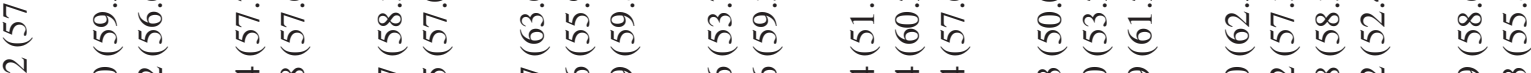

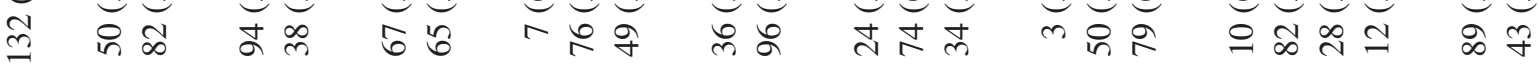

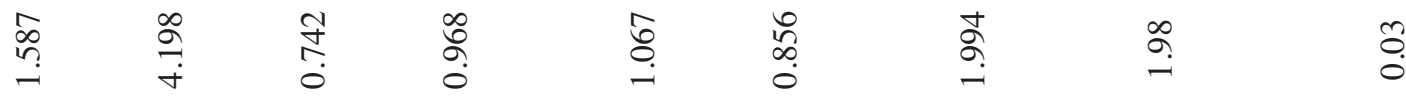

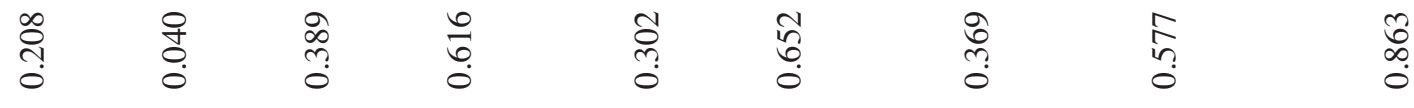

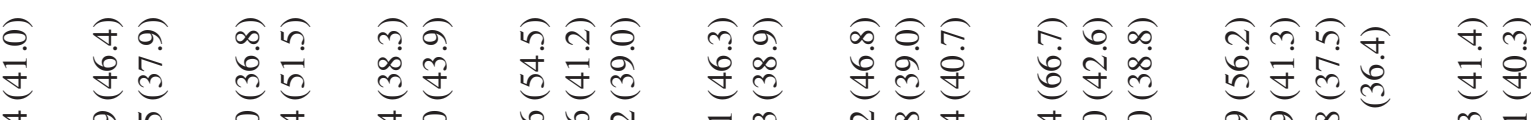
व

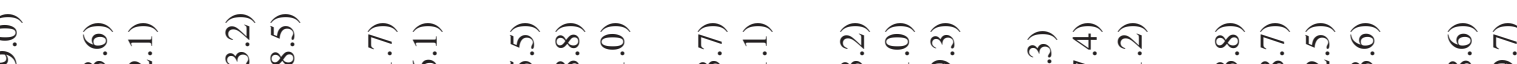
हृत्र

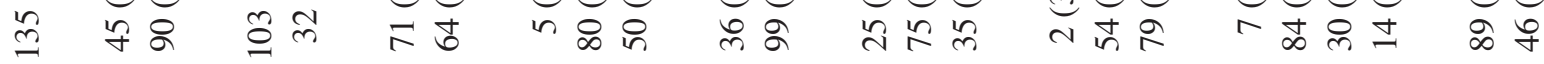
สิ क年 
Table V. Associations between Twist, Snail and Slug protein expression in esophageal squamous cell carcinoma.

A, Twist and Snail/Slug

\begin{tabular}{lllll}
\hline & \multicolumn{2}{c}{ Twist, n (\%) } & & \\
\cline { 2 - 3 } Protein & Positive & Negative & P-value & $\chi^{2}$ \\
\hline Snail & & & 0.013 & 6.223 \\
Positive & $87(64.4)$ & $45(47.9)$ & & \\
Negative & $48(35.6)$ & $49(52.1)$ & & \\
Slug & & & 0.994 & 0.001 \\
Positive & $66(48.9)$ & $46(48.9)$ & & \\
Negative & $69(51.1)$ & $48(51.1)$ & &
\end{tabular}

B, Snail and Slug

\begin{tabular}{lllll}
\hline & \multicolumn{2}{c}{ Snail, $\mathrm{n}(\%)$} & & \\
\cline { 2 - 3 } Protein & Positive & Negative & P-value & $\chi^{2}$ \\
\hline Slug & & & $<0.001$ & 24.340 \\
Positive & $83(62.9)$ & $29(29.9)$ & & \\
Negative & $49(37.1)$ & $68(70.1)$ & & \\
\hline
\end{tabular}

Analyzed using a $\chi^{2}$ test.

significantly higher than that with vascular invasion (32.6\%). However, no significant association was detected between the positive expression of Snail and any of the clinicopathological parameters (Table IV).

Analysis of the associations between protein and $m R N A$ expression of Twist, Snail and Slug. According to the $\chi^{2}$ test analysis of 229 cases of esophageal squamous cell carcinoma, the positive expression rate of Twist in patients with Snail positive expression was $64.4 \%$. In patients with negative Twist expression, the negative expression rate of Snail was $52.1 \%$, suggesting that there was a significant difference in protein expression between them in $\operatorname{ESCC}(\mathrm{P}=0.013$; Table V). In addition, in patients with positive Snail expression, the positive expression rate of Slug was $62.9 \%$. When Snail was negative, the negative expression rate of Slug was $70.1 \%$. The results revealed that there was a difference in the expression of Snail and Slug protein in ESCC $(\mathrm{P}<0.001$; Table V). However, there was no significant difference in protein expression between Twist and Slug $(\mathrm{P}=0.994$; Table V).

The results of the analysis of Twist, Snail and Slug mRNA expression levels in fresh frozen tissues using paired samples t-tests are shown in Table VI. The ESCC and adjacent tissues significantly differed in the mRNA expression of Twist $(\mathrm{t}=4.044, \mathrm{P}<0.001$; Table VI and Fig. 2A). The expression of Twist mRNA in ESCC was significantly higher than that in the adjacent normal mucosa. The difference in the mRNA expression of transcription factor Slug was also statistically significant in ESCC ( $\mathrm{t}=-5.687, \mathrm{P}<0.001$; Table VI and Fig. 2B); however, the expression of Slug in esophageal normal mucosa 
Table VI. Differential expression of Twist, Snail and Slug in esophageal squamous cell carcinoma.

\begin{tabular}{lccccrr}
\hline Protein & Mean & SD & SE & $95 \%$ CI & t & P-value \\
\hline Twist & 2.220 & 2.957 & 5.491 & $(3.345,1.096)$ & 4.044 & $<0.001$ \\
Slug & -2.698 & 2.555 & 4.745 & $(-1.726,-3.670)$ & -5.687 & $<0.001$ \\
Snail & 2.799 & 1.380 & 2.563 & $(8.050,-2.451)$ & 1.092 & 0.284 \\
\hline
\end{tabular}

Mean, mean difference in mRNA expression between ESCC and adjacent tissues; SD, standard deviation of the difference; SE, standard error of the mean difference; $95 \% \mathrm{CI}, 95 \%$ confidence internal of the difference.
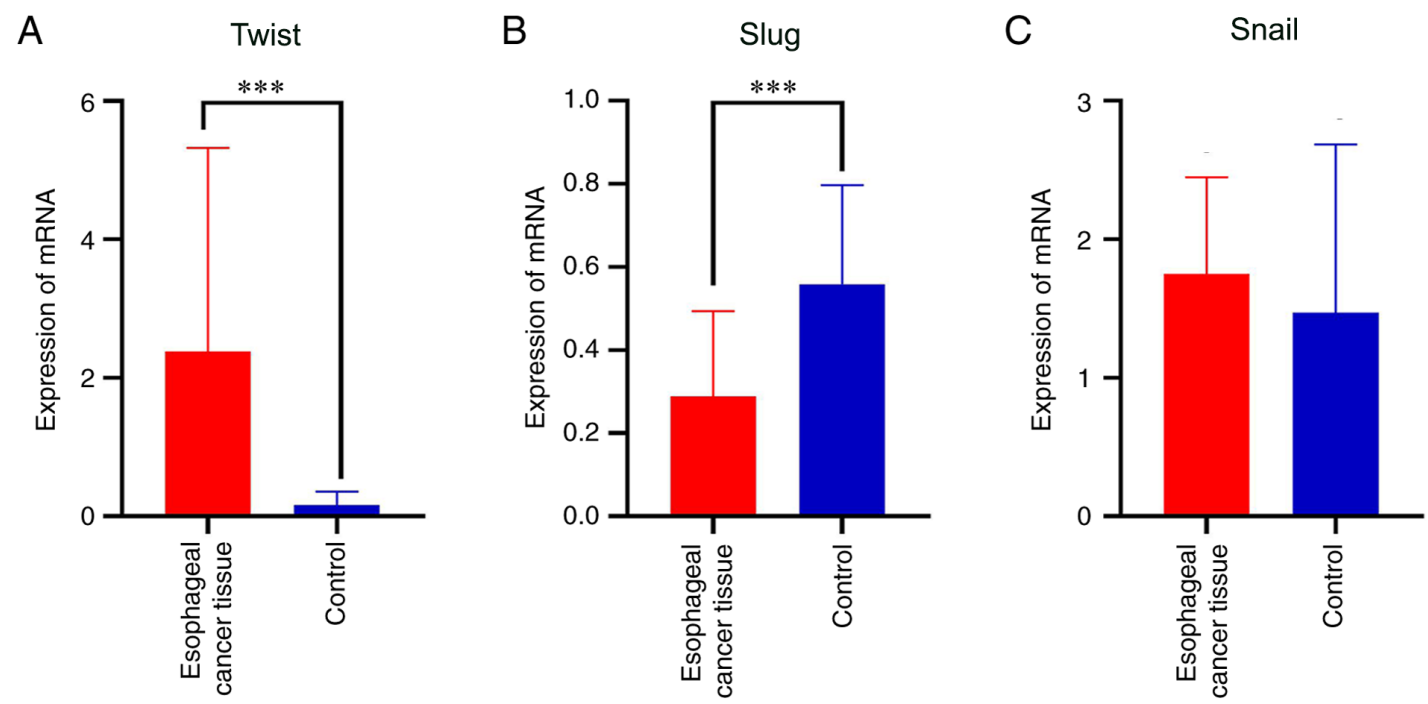

Figure 2. mRNA expression of Twist, Slug and Snail in ESCC and normal esophageal mucosa. The data are presented as the mean $+\mathrm{SD}$. ${ }^{* * *} \mathrm{P}<0.001 .(\mathrm{A}) \mathrm{Twist}$, (B) Slug and (C) Snail in ESCC and control tissues. ESCC, esophageal squamous cell carcinoma; control, normal esophageal mucosal tissues.

was higher than that in ESCC tissue. No significant difference in the mRNA expression of Snail was detected between the ESCC and normal mucosal tissues $(\mathrm{t}=1.092, \mathrm{P}=0.284$; Table VI and Fig. 2C).

Pearson's correlation analysis revealed that there was a positive correlation between the mRNA expression of Twist and that of Snail in ESCC ( $\mathrm{r}=0.369, \mathrm{P}=0.024$; Fig. 3A), indicating that when the mRNA expression of Twist was high, the mRNA expression of Snail was also high. However, no significant correlation was observed between Slug and Snail ( $\mathrm{r}=0.065, \mathrm{P}=0.368$; Fig. 3B), and Twist and Slug ( $\mathrm{r}=0.262$, $\mathrm{P}=0.085$; Fig. $3 \mathrm{C}$ ) expression.

Influence of Twist, Snail, Slug and clinicopathological parameters on the prognosis of ESCC. The influence of clinicopathological parameters on the prognosis of ESCC was analyzed (Table VII). Kaplan-Meier survival analysis showed that TNM stage $(\mathrm{P}=0.027$; Fig. $4 \mathrm{~A})$, lymph node metastasis $(\mathrm{P}=0.012$; Fig. 4B), nerve invasion $(\mathrm{P}=0.001$; Fig. 4C) and postoperative radiotherapy or chemotherapy $(\mathrm{P}<0.001$; Fig. 4D) had an impact on the overall survival of patients with ESCC. Using the Cox proportional hazards model (Table VIII), it was found that nerve invasion $(\mathrm{P}=0.002)$, and postoperative radiotherapy or chemotherapy $(\mathrm{P}<0.001)$ had an effect on the overall duration of survival; therefore, nerve invasion and postoperative radiotherapy or chemotherapy may be used as independent prognostic factors for ESCC. However, lymph node metastasis $(\mathrm{P}=0.145)$ and TNM stage $(\mathrm{P}=0.149)$ were not found to significantly affect the survival status of patients with ESCC. The overall survival time of patients with neurological invasion was shorter, and the risk of mortality was 1.78 times higher in patients with neurological invasion than in patients without [hazard ratio $(\mathrm{HR})=1.78$ ]. The overall survival time of patients with ESCC who received postoperative radiotherapy or chemotherapy was significantly prolonged $(\mathrm{P}<0.001)$, and the death rate of patients who received radiotherapy or chemotherapy was less that of patients who did not $(\mathrm{HR}=0.545)$.

The effects of Twist, Snail and Slug expression on the overall survival of patients with ESCC were also analyzed (Table IX). The results did not identify a statistically significant effect of Twist ( $\mathrm{P}=0.154$; Fig. 5A) or Slug ( $\mathrm{P}=0.772$; Fig. 5C) on ESCC prognosis, but revealed a significant effect of Snail on the overall survival of patients with $\operatorname{ESCC}(\mathrm{P}=0.008$; Fig. 5B). Cox multivariate model analysis revealed that Snail was an independent factor $(\mathrm{P}=0.033)$ affecting the overall survival of patients with ESCC (Table VIII). The prognosis of patients who were Snail positive was poor, and their overall survival duration was shorter than that of patients who were Snail negative ( $\mathrm{HR}=1.422)$.

Kaplan-Meier analysis showed that TNM staging ( $\mathrm{P}=0.019$; Fig. 4E), lymph node metastasis $(\mathrm{P}=0.01$; Fig. 4F) and nerve invasion $(\mathrm{P}=0.046$; Fig. $4 \mathrm{G})$ had a significant effect 

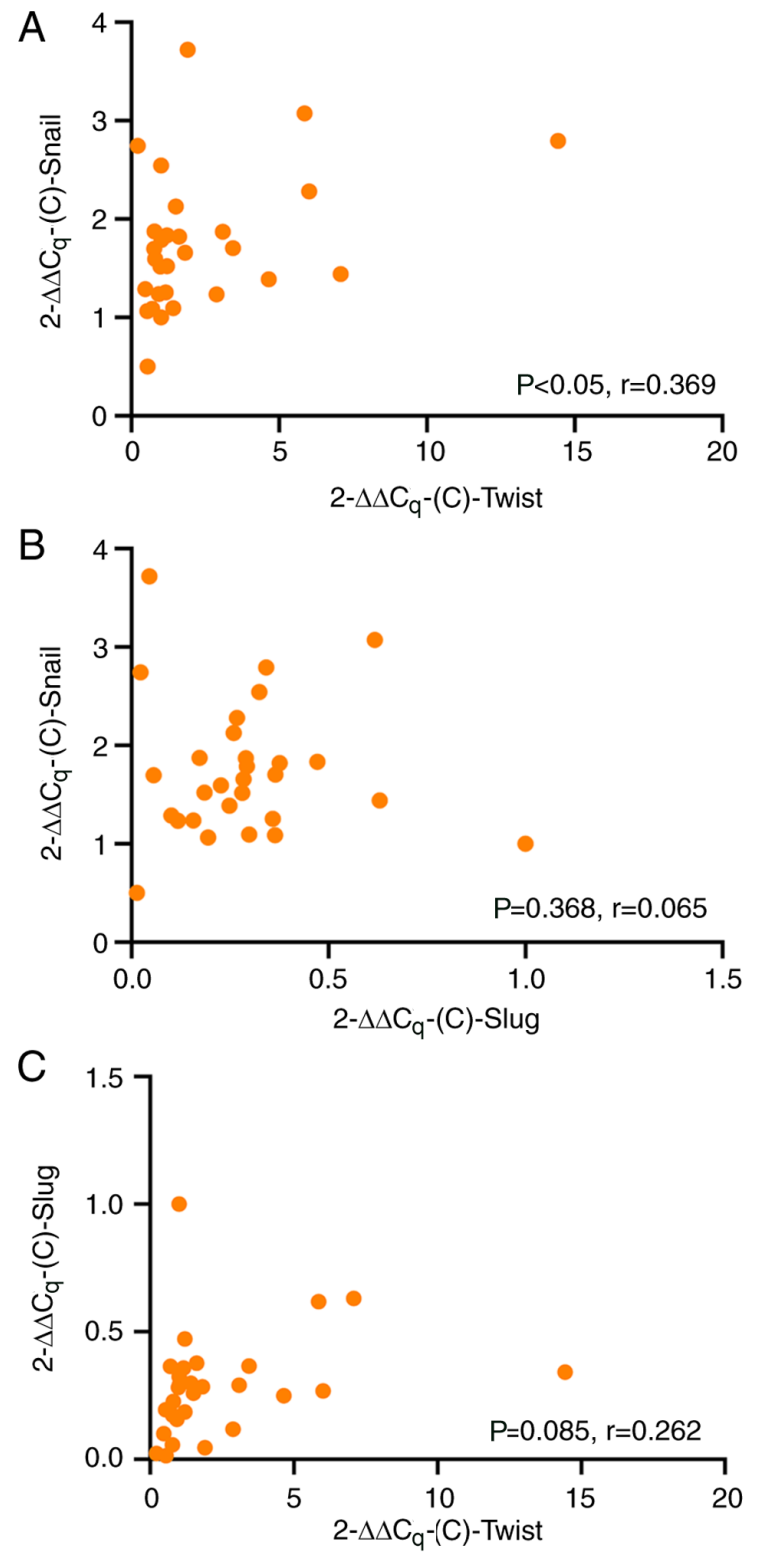

Figure 3. Correlation between mRNA expression levels of Twist, Snail and Slug. Pearson's correlation analysis of the mRNA levels of (A) Twist and Snail, (B) Slug and Snail and (C) Twist and Slug.

on progression-free survival in ESCC (Table VII), while no significant association of Twist $(\mathrm{P}=0.142$; Fig. 5D), Snail $(\mathrm{P}=0.192$; Fig. 5E) or Slug $(\mathrm{P}=0.627$; Fig. $5 \mathrm{~F})$ with progression-free survival in ESCC was observed (Table IX). Using Cox multivariate analysis (Table $\mathrm{X}$ ), it was found that nerve invasion $(\mathrm{P}=0.05)$ was an independent factor affecting the progression-free survival of patients with ESCC.

Effects of Twist, Snail and Slug co-expression on the prognosis of ESCC. Kaplan-Meier analysis showed that the co-expression of Twist and Snail ( $\mathrm{P}=0.035$; Fig. 6B), and Snail and Slug $(\mathrm{P}=0.019$; Fig. 6C) had a significant effect on the overall survival of patients with ESCC (Table XI), while the co-expression of Twist, Snail and Slug $(\mathrm{P}=0.137$; Fig. 6A), and Twist and Slug $(\mathrm{P}=0.532$; Fig. 6D) had no effect on overall survival (Table XI). The results also indicate that the co-expression of Twist, Snail and Slug ( $\mathrm{P}=0.133$; Fig. 6E),
Twist and Snail $(\mathrm{P}=0.208$; Fig. $6 \mathrm{~F})$, Snail and Slug $(\mathrm{P}=0.515$; Fig. 6G) and Twist and Slug $(\mathrm{P}=0.220$; Fig. $6 \mathrm{H})$ had no effect on the progression-free survival of the 229 patients with ESCC (Table XI). These results suggest that the simultaneous inhibition of Twist and Snail protein expression would be conducive to prolonging the overall survival of patients with ESCC.

\section{Discussion}

Surgical resection is the main treatment for early esophageal cancer; however, the treatment of patients with recurrence or progression is challenging. The identification of highly specific molecular targets for the clinical treatment and prognosis evaluation of patients with advanced esophageal cancer is likely to have practical consequences. Therefore, the aim of the present study was to investigate the expression of Twist, Slug and Snail in ESCC and their prognostic significance.

Kazakhs have a high incidence of ESCC in Xinjiang. Zheng et al (27) revealed that ESCC is associated with Kazakhs' habits of smoking, drinking alcohol and drinking hot milk tea. The present study revealed that there were significant differences in age, tumor location and vascular invasion between Han and Kazakh patients. The proportion of Kazakh patients $<60$ years old was higher than that of Han nationality, which indicates that Kazakh patients with esophageal cancer are mainly young. The incidence of esophageal cancer in the middle and lower parts of the esophagus in Kazakh patients was higher than that in the upper part. It is suggested that changing diet and lifestyle may decrease the incidence rate of ESCC.

Twist has been shown to be important indicator in breast cancer, with a meta-analysis showing that Twist expression is associated with increased tumor size, lymph node involvement, high grade and human epidermal growth factor receptor 2 positivity (28). In ESCC, it has been found that the expression of Twist is significantly associated with lymph node metastasis, and the overexpression of Twist can significantly increase the invasion of ESCC cells and their expression of vascular endothelial growth factor C (VEGF-C), while the knockdown of Twist has the opposite effects, as confirmed by immunohistochemical detection of the co-expression of Twist and VEGF-C in ESCC (29).

In the present study, the positive expression rate of Twist protein in ESCC was higher than that in normal esophageal mucosa, and the RT-qPCR results confirmed that Twist was highly expressed in ESCC at the transcriptional level. Among the 229 cases of ESCC analyzed using immunohistochemistry, Twist was positive in 135 (59.0\%), and negative in 94 cases (41.0\%). The expression of Twist in ESCC was found to be associated with the sex of the patient. The positive Twist expression rate in male patients was higher than that in female patients; if male patients were positive for Twist expression, it was more likely to indicate ESCC. Therefore, it is predicted that Twist may be a target gene for the diagnosis of ESCC.

High expression levels of Slug are generally considered to promote tumorigenesis and development. It has been reported that Slug is associated with the invasion, migration and cell regulation of tumor cells and, as an important transcription factor during EMT, can directly inhibit E-cadherin transcription and induce EMT, thereby promoting tumor 
Table VII. Influence of clinicopathological parameters on the prognosis of patients with esophageal squamous cell carcinoma.

\begin{tabular}{|c|c|c|c|c|c|c|c|c|}
\hline \multirow[b]{2}{*}{$\begin{array}{l}\text { Clinicopathological } \\
\text { parameters }\end{array}$} & \multicolumn{4}{|c|}{ OS } & \multicolumn{4}{|c|}{ PFS } \\
\hline & $\begin{array}{c}\text { Mean } \\
\text { survival } \\
\text { (months) }\end{array}$ & $\begin{array}{l}\text { Median } \\
\text { survival } \\
\text { (months) }\end{array}$ & $\begin{array}{c}\text { Log rank } \\
\text { (Mantel-Cox) }\end{array}$ & P-value & $\begin{array}{c}\text { Mean } \\
\text { survival } \\
\text { (months) }\end{array}$ & $\begin{array}{l}\text { Median } \\
\text { survival } \\
\text { (months) }\end{array}$ & $\begin{array}{c}\text { Log rank } \\
\text { (Mantel-Cox) }\end{array}$ & P-value \\
\hline Age, years & & & 0.087 & 0.768 & & & 0.122 & 0.726 \\
\hline$\leq 60$ & 27.682 & 24 & & & 21.197 & 16 & & \\
\hline$>60$ & 27.615 & 22 & & & 20.364 & 12 & & \\
\hline Sex & & & 1.495 & 0.222 & & & 0.627 & 0.429 \\
\hline Male & 26.485 & 24 & & & 20.224 & 13 & & \\
\hline Female & 29.780 & 30 & & & 22.422 & 12 & & \\
\hline Ethnicity & & & 0.033 & 0.857 & & & 0.178 & 0.673 \\
\hline Han & 26.454 & 24 & & & 20.811 & 13 & & \\
\hline Kazakh & 28.189 & 24 & & & 20.187 & 12 & & \\
\hline Tumor location & & & 1.429 & 0.489 & & & 1.127 & 0.569 \\
\hline Upper & 19.515 & 2 & & & 19.000 & 2 & & \\
\hline Middle & 27.575 & 24 & & & 21.739 & 12 & & \\
\hline Lower & 27.030 & 24 & & & 19.001 & 15 & & \\
\hline Tumor size & & & 0.575 & 0.448 & & & 0.522 & 0.47 \\
\hline$<3 \mathrm{~cm}$ & 28.223 & 32 & & & 22.102 & 20 & & \\
\hline$\geq 3 \mathrm{~cm}$ & 26.943 & 20 & & & 20.169 & 12 & & \\
\hline Differentiation & & & 4.314 & 0.116 & & & 1.678 & 0.432 \\
\hline Low & 23.756 & 18 & & & 19.082 & 16 & & \\
\hline Medium & 25.890 & 24 & & & 19.992 & 13 & & \\
\hline High & 34.360 & 24 & & & 24.594 & 11 & & \\
\hline Depth of invasion & & & 2.054 & 0.358 & & & 2.484 & 0.289 \\
\hline Mucosal & 37.833 & 48 & & & 34.000 & 48 & & \\
\hline Muscle & 28.697 & 24 & & & 20.375 & 12 & & \\
\hline Full & 25.635 & 22 & & & 20.182 & 12 & & \\
\hline TNM stage & & & 9.200 & 0.027 & & & 10.006 & 0.019 \\
\hline I & 35.266 & 36 & & & 23.899 & 10 & & \\
\hline II & 29.520 & 28 & & & 23.049 & 18 & & \\
\hline III & 20.894 & 18 & & & 14.932 & 12 & & \\
\hline IV & 19.756 & 13 & & & 12.427 & 9 & & \\
\hline Lymph node metastasis & & & 6.270 & 0.012 & & & 6.698 & 0.010 \\
\hline No & 30.248 & 31 & & & 23.134 & 18 & & \\
\hline Yes & 22.128 & 15 & & & 15.776 & 12 & & \\
\hline Vascular invasion & & & 1.670 & 0.196 & & & 0.349 & 0.555 \\
\hline No & 28.826 & 24 & & & 21.083 & 12 & & \\
\hline Yes & 22.719 & 22 & & & 18.200 & 12 & & \\
\hline Nerve invasion & & & 10.255 & 0.001 & & & 3.990 & 0.046 \\
\hline No & 30.223 & 24 & & & 22.089 & 14 & & \\
\hline Yes & 18.567 & 10 & & & 16.090 & 10 & & \\
\hline $\begin{array}{l}\text { Radiotherapy or } \\
\text { chemotherapy }\end{array}$ & & & 10.202 & $<0.001$ & & & 3.185 & 0.074 \\
\hline No & 23.157 & 18 & & & 24.228 & 12 & & \\
\hline Yes & 35.152 & 28 & & & 18.907 & 18 & & \\
\hline
\end{tabular}

OS, overall survival; PFS, progression-free survival.

progression (30). Furthermore, Slug has been shown to promote lymph node metastasis in oropharyngeal squamous cell carcinoma (31). Hasan et al (32) studied the association between the expression of Slug and the clinicopathological parameters and prognosis of patients with ESCC, and found that Slug expression increased during in the early stages of 

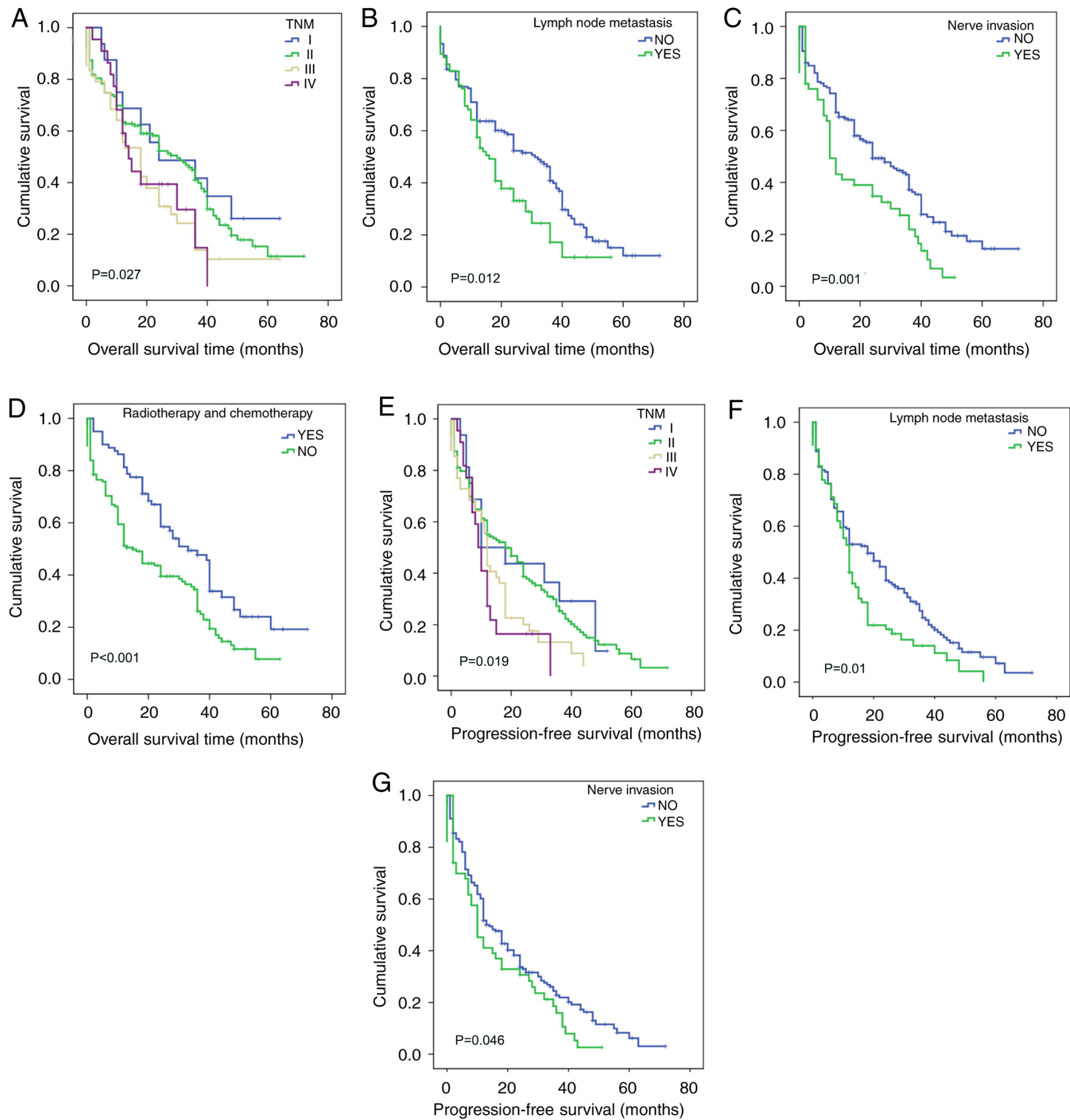

Figure 4. Overall survival and progression-free-survival analysis of the influence of clinicopathological parameters on ESCC. Overall survival analysis according to (A) TNM stage, (B) lymph node metastasis, (C) nerve invasion, (D) radiotherapy or chemotherapy. Progression-free survival analysis according to (E) TNM stage, (F) lymph node metastasis and (G) nerve invasion. ESCC, esophageal squamous cell carcinoma.

ESCC development, and persisted as the disease progressed. Therefore, it was suggested that Slug can be used as a diagnostic biomarker, as well as a predictor of poor prognosis, to aid the early detection of the possibility of postoperative esophageal cancer recurrence.

In the present study, Slug expression was positive in 112 (48.9\%) and negative in 117/229 (51.1\%) cases of ESCC. When the association of Slug expression with clinicopathological parameters was analyzed, it was found that the expression of Slug differed according to the differentiation degree, TNM stage and vascular invasion status of ESCC. The positive expression rate of Slug in poorly differentiated ESCC was lower that than in highly differentiated ESCC. Among the various TNM stages, the highest Slug positive rate was detected in TNM stage I. The positive expression rate of Slug in esophageal carcinoma without vascular invasion was $52.7 \%$, which was significantly higher than that in esophageal carcinoma with vascular invasion $(32.6 \%)$. These results suggest that Slug is a tumor suppressor gene in ESCC. In addition, RT-qPCR showed that the mRNA expression of Slug 
Table VIII. Cox analysis of the overall survival of patients with esophageal squamous cell carcinoma.

\begin{tabular}{lccccccr}
\hline \multirow{2}{*}{ Variables } & \multicolumn{1}{c}{ Wald } & P-value & HR & Lower & HR 95\% CI \\
\hline Snail & B & SE & Higher \\
Lymph node metastasis & 0.352 & 0.165 & 4.531 & 0.033 & 1.422 & 1.028 & 1.966 \\
TNM stage & 0.33 & 0.226 & 2.128 & 0.145 & 1.391 & 0.893 & 2.168 \\
Nerve invasion & 0.208 & 0.144 & 2.077 & 0.149 & 1.231 & 0.928 & 1.634 \\
Radiotherapy or chemotherapy & 0.577 & 0.182 & 10.036 & 0.002 & 1.78 & 1.246 & 2.543 \\
& -0.607 & 0.174 & 12.207 & $<0.001$ & 0.545 & 0.388 & 0.766 \\
\hline
\end{tabular}

HR, hazard ratio.

Table IX. Effects of Twist, Snail and Slug expression on the prognosis of patients with esophageal squamous cell carcinoma.

\begin{tabular}{|c|c|c|c|c|c|c|c|c|}
\hline \multirow[b]{2}{*}{ Protein } & \multicolumn{4}{|c|}{ OS } & \multicolumn{4}{|c|}{ PFS } \\
\hline & $\begin{array}{c}\text { Mean } \\
\text { survival } \\
\text { (months) }\end{array}$ & $\begin{array}{c}\text { Median } \\
\text { survival } \\
\text { (months) }\end{array}$ & $\begin{array}{c}\text { Log rank } \\
\text { (Mantel-Cox) }\end{array}$ & P-value & $\begin{array}{c}\text { Mean } \\
\text { survival } \\
\text { (months) }\end{array}$ & $\begin{array}{l}\text { Median } \\
\text { survival } \\
\text { (months) }\end{array}$ & $\begin{array}{c}\text { Log rank } \\
\text { (Mantel-Cox) }\end{array}$ & P-value \\
\hline Twist & & & 2.033 & 0.154 & & & 2.158 & 0.142 \\
\hline Positive & 26.112 & 18 & & & 19.256 & 12 & & \\
\hline Negative & 29.408 & 27 & & & 23.012 & 18 & & \\
\hline Snail & & & 7.076 & 0.008 & & & 2.158 & 0.192 \\
\hline Positive & 23.476 & 18 & & & 19.291 & 12 & & \\
\hline Negative & 33.169 & 36 & & & 23.772 & 18 & & \\
\hline Slug & & & 0.126 & 0.772 & & & 0.236 & 0.627 \\
\hline Positive & 26.962 & 18 & & & 19.798 & 12 & & \\
\hline Negative & 27.399 & 24 & & & 21.364 & 13 & & \\
\hline
\end{tabular}

OS, overall survival; PFD, progression-free survival.

Table X. Cox-analysis of progression-free survival in patients with esophageal squamous cell carcinoma.

\begin{tabular}{lccccccc}
\hline Variables & \multirow{2}{*}{ SE } & Wald & P-value & HR & Lower & Upper \\
\hline Lymph node metastasis & 0.222 & 0.212 & 1.102 & 0.294 & 1.249 & 0.825 & 1.891 \\
TNM stage & 0.192 & 0.139 & 1.913 & 0.167 & 1.212 & 0.923 & 1.59 \\
Nerve invasion & 0.341 & 0.174 & 3.858 & 0.05 & 1.407 & 1.001 & 1.978 \\
\hline
\end{tabular}

HR, hazard ratio.

in esophageal normal mucosa was higher than that in ESCC $(\mathrm{P}<0.001)$. These results were confirmed at the transcriptional level. In the study by Cui et al (33), Slug was found to play an anticancer role in the progression of cervical cancer. The mechanism was suggested to be that Slug, by combining with the E-box motif of the AKT1 gene promoter, trans-inhibits the expression of AKT1, which upregulates p21/p27 and/or downregulates the activity of the $\mathrm{Wnt} / \beta$-catenin signaling pathway, thereby inhibiting the proliferation of cervical cancer cells and tumor formation. In the present study, no marked difference was found in the expression of Slug between ESCC and the corresponding adjacent tissues by immunohistochemistry, while the detection results of Slug mRNA showed that its expression was higher in the adjacent normal tissues than in ESCC. These results suggest that Slug may be a tumor suppressor gene in ESCC. However, no significant associations between Snail expression and the clinicopathological parameters of patients with ESCC were detected herein. 
A

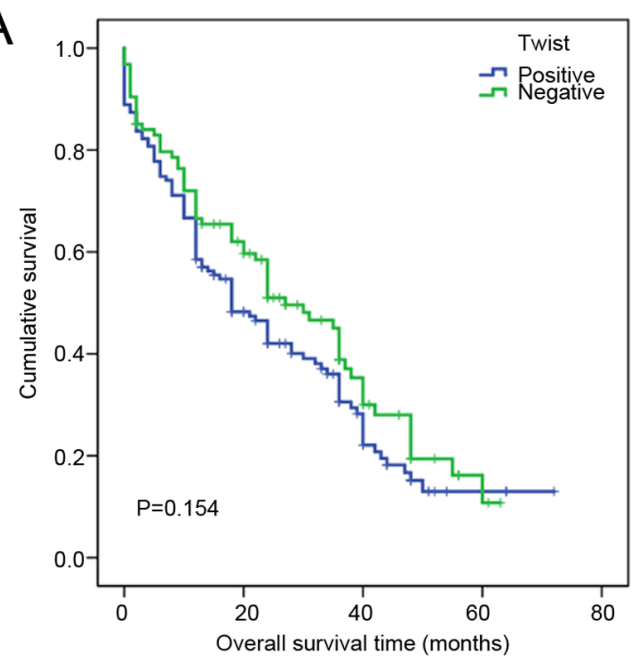

C

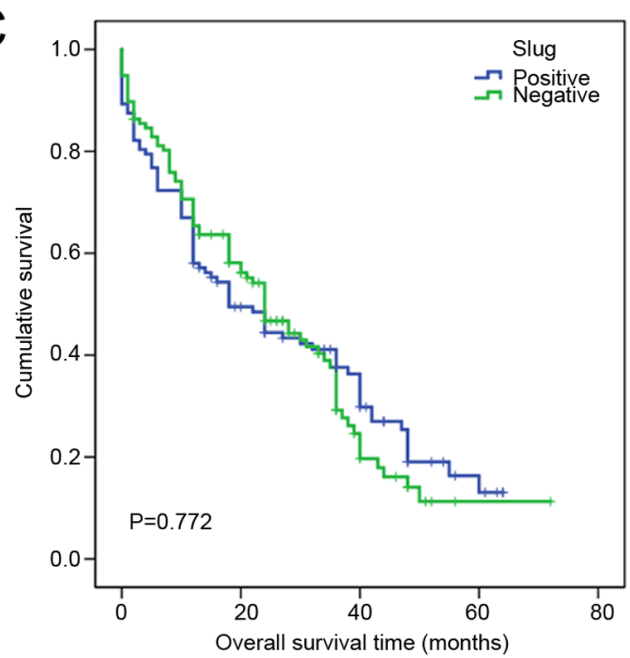

E

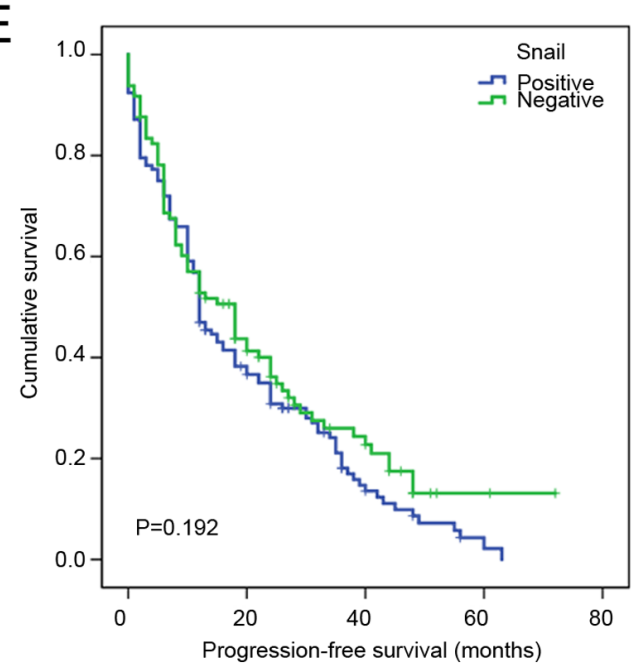

B

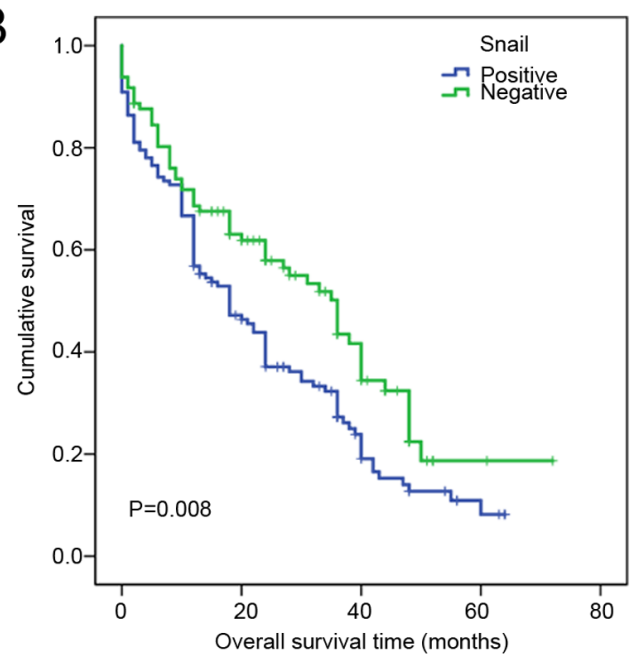

D

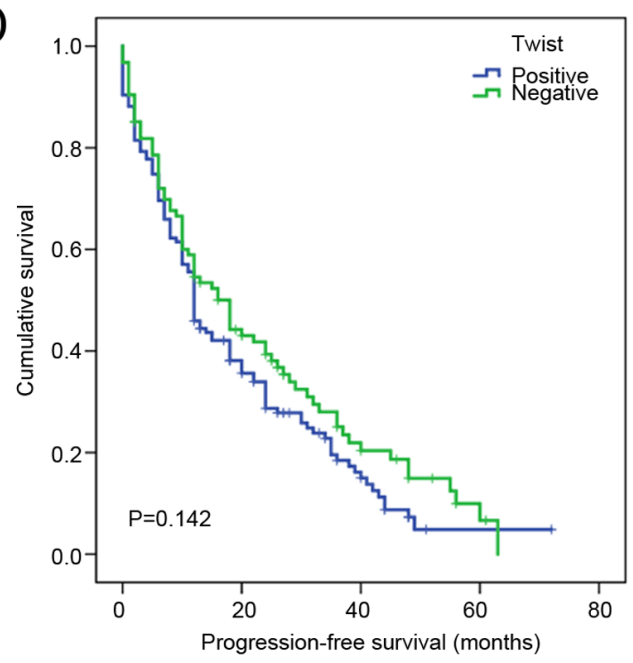

$\mathrm{F}$

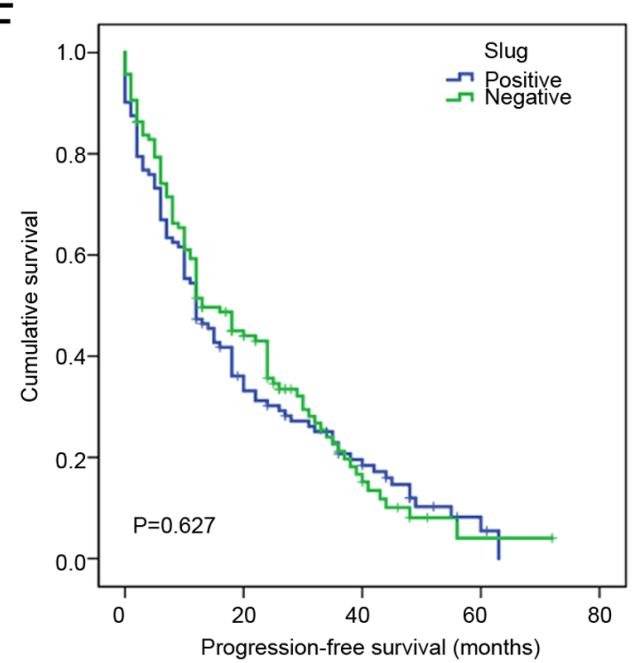

Figure 5. Effects of Twist, Snail and Slug expression on the prognosis of patients with ESCC. Overall survival analysis according to (A) Twist, (B) Snail and (C) Slug expression status. Progression-free survival analysis according to (D) Twist, (E) Snail and (F) Slug expression status ESCC, esophageal squamous cell carcinoma.

The effects of Twist, Slug, Snail and clinicopathological parameters on the prognosis of esophageal cancer were also evaluated in the present study. Twist has been demonstrated to play an important role in a variety of invasive cancers, such as breast (17), lung (18) and prostate cancer (19). In one study, Twist was shown to be involved in nicotine-derived nitrosamine ketone-induced lung cancer cell migration and invasion (18). Lyu et al (19) demonstrated that Twist is a 
Table XI. Effects of co-expression of Twist, Snail and Slug on the prognosis of patients with esophageal squamous cell carcinoma.

\begin{tabular}{|c|c|c|c|c|c|c|c|c|c|}
\hline \multirow[b]{2}{*}{ Co-expression } & \multirow[b]{2}{*}{ No. } & \multicolumn{4}{|c|}{ OS } & \multicolumn{4}{|c|}{ PFS } \\
\hline & & $\begin{array}{c}\text { Mean } \\
\text { survival } \\
\text { (months) }\end{array}$ & $\begin{array}{l}\text { Median } \\
\text { survival } \\
\text { (months) }\end{array}$ & $\begin{array}{c}\text { Log rank } \\
\text { (Mantel-Cox) }\end{array}$ & P-value & $\begin{array}{c}\text { Mean } \\
\text { survival } \\
\text { (months) }\end{array}$ & $\begin{array}{l}\text { Median } \\
\text { survival } \\
\text { (months) }\end{array}$ & $\begin{array}{c}\text { Log rank } \\
\text { (Mantel-Cox) }\end{array}$ & $\mathrm{P}$-value \\
\hline Twist/Snail/Slug & & & & 5.531 & 0.137 & & & 5.598 & 0.133 \\
\hline$+/+/+$ & 52 & 21.728 & 12 & & & 15.274 & 11 & & \\
\hline$+/+/-$ & 80 & 25.799 & 24 & & & 21.582 & 18 & & \\
\hline$+/-/-$ & 63 & 33.293 & 33 & & & 24.488 & 12 & & \\
\hline$-/-/-$ & 34 & 26.352 & 31 & & & 20.262 & 18 & & \\
\hline Twist/Snail & & & & 8.593 & 0.035 & & & 4.551 & 0.208 \\
\hline$+/+$ & 87 & 22.113 & 16 & & & 17.073 & 12 & & \\
\hline$+/-$ & 48 & 32.297 & 36 & & & 23.939 & 12 & & \\
\hline$-/+$ & 45 & 26.183 & 24 & & & 23.229 & 16 & & \\
\hline$-/-$ & 49 & 32.263 & 35 & & & 22.549 & 18 & & \\
\hline Snail/Slug & & & & 9.917 & 0.019 & & & 2.287 & 0.515 \\
\hline$+/+$ & 83 & 23.001 & 13 & & & 18.444 & 12 & & \\
\hline$+/-$ & 49 & 23.27 & 24 & & & 20.255 & 16 & & \\
\hline$-/+$ & 29 & 37.53 & 48 & & & 23.682 & 18 & & \\
\hline$-/-$ & 68 & 29.704 & 28 & & & 22.654 & 13 & & \\
\hline Twist/Slug & & & & 2.198 & 0.532 & & & 4.412 & 0.22 \\
\hline$+/+$ & 66 & 24.941 & 14 & & & 16.368 & 12 & & \\
\hline$+/-$ & 69 & 26.021 & 24 & & & 21.53 & 12 & & \\
\hline$-/+$ & 46 & 30.077 & 27 & & & 24.077 & 16 & & \\
\hline$-/-$ & 48 & 27.544 & 31 & & & 21.207 & 18 & & \\
\hline
\end{tabular}

OS, overall survival; PFS, progression-free survival.

prognostic marker of prostate cancer, and identified potential downstream target and genes, which may be useful for predicting the prognosis of Twist-mediated prostate cancer. In addition, Sun and Liu (34) reported that the upregulation of Twist activates the Wnt/ $\beta$-catenin signaling pathway and promotes cervical cancer. We hypothesize that Twist may also be of significance in the development of ESCC. According to the results of the present study, Twist is highly expressed in ESCC. However, Kaplan-Meier survival analysis indicated that there was no significant difference in the prognosis of ESCC between Twist-positive and -negative cases, although a trend for poor overall survival in Twist positive cases was shown in the survival curves.

In studies conducted by Salehi et al (35) and Shenas et al (36), when Snail was silenced, the expression of vimentin was decreased, E-cadherin was induced and EMT was inhibited, and Snail was indicated to play a crucial role in the survival of bladder cancer. The high expression of Snail has also been reported to indicate a poor prognosis in patients with infiltrative breast lesions (37). In the present study, the results of Kaplan-Meier survival analysis showed that the overall survival for cases with positive Snail expression was significantly worse than that for those with negative expression, suggesting that the patients who were positive for Snail expression had a poor prognosis and shorter survival time. Multivariate Cox analysis indicated that Snail is an independent prognostic factor for ESCC. This is consistent with the results of several previous studies $(35,36)$.

Kaplan-Meier survival analysis demonstrated that patients with lymph node metastasis $(\mathrm{P}=0.012)$, a higher TNM stage $(\mathrm{P}=0.027)$ and nerve invasion $(\mathrm{P}<0.001)$, or without postoperative radiotherapy or chemotherapy $(\mathrm{P}<0.001)$, had a shorter overall survival. Multivariate Cox analysis indicated that nerve invasion and postoperative radiotherapy or chemotherapy are independent prognostic factors for ESCC. When progression-free survival in ESCC was analyzed, the results indicated that lower TNM stages were associated with longer progression-free survival. Patients without nerve invasion and lymph node metastasis also had a longer progression-free survival. This suggests that postoperative radiotherapy or chemotherapy can prolong the time taken for ESCC to recur and metastasize, as well as the associated mortality.

The Twist/Snail axis has been demonstrated to be the key to tropomyosin receptor kinase B-induced EMT, apoptosis inhibition and metastasis. Twist, as the upstream gene of Snail, affects the occurrence of EMT, and regulates and induces the expression of E-cadherin in Snail, thus increasing the risk of tumor metastasis (38). A study on the expression of Snail and Twist revealed varying degrees of interdependence; Snail and Twist were shown to cooperate 

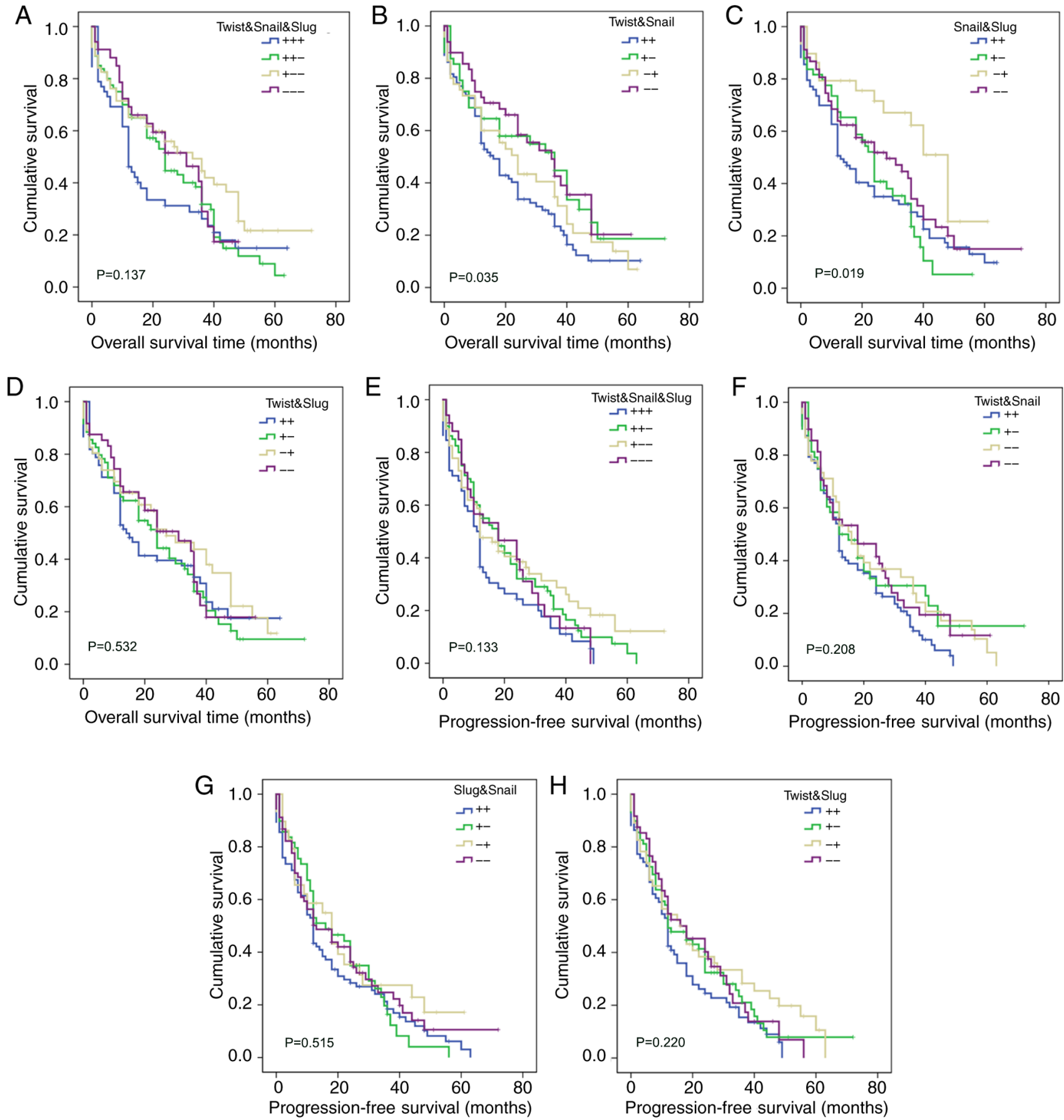

Figure 6. Effects of co-expression of Twist, Snail and Slug on the prognosis of patients with ESCC. Overall survival analysis according to (A) Twist, Snail and Slug, (B) Twist and Snail, (C) Snail and Slug and (D) Twist and Slug co-expression, Progression-free survival analysis according to (E) Twist, Snail and Slug, (F) Twist and Snail, (G) Snail and Slug and (H) Twist and Slug co-expression. ESCC, esophageal squamous cell carcinoma.

in the induction of zinc finger E-box-binding homeobox 1, while the absence of Twist inhibited the upregulatory effect of TNF- $\beta$ on Snail, but Snail was essential for the rapid increase in Twist protein and upregulation of Twist mRNA induced by TNF- $\beta$ (39).

In the present study, a significant difference was detected between the protein expression of Twist and that of Snail; when Twist was highly expressed, Snail was also likely to be highly expressed. A significant correlation between Twist and Snail was also observed at the transcriptional level. We hypothesize that Twist and Snail are co-expressed, and their co-expression suggests a poor prognosis in ESCC patients. Although no significant correlation was observed between Twist and Slug, a positive correlation was observed for Slug and Snail proteins $(\mathrm{r}=0.326 ; \mathrm{P}<0.001)$. Considering that Slug is a member of the Snail family, the functional structures of Slug and Snail have a certain similarity. However, no significant correlation between Slug and Snail was identified at the transcriptional level. We hypothesize that the expression of Slug in ESCC may be inhibited at the transcriptional level. However, as the sample size was too small, more experiments are required to confirm this. 
Twist, Slug and Snail are key transcription factors in tumorigenesis and development. Twist and Snail have been shown to affect the epithelial stromal transformation of odontogenic epithelial tumors, with the expression of Twist being associated with the aggressive behavior of the tumors, whose occurrence and development may involve the Twist/Snail pathway, while Snail may mediate interaction between the tumors and stroma (40). In a study of chronic obstructive pulmonary disease (COPD) conducted by Mahmood et al (41), it was found that the transcription factor complex $\beta$-catenin-Snail1-Twist was upregulated in smokers and patients with COPD, and translocated to the nucleus. Furthermore, its expression was closely associated with EMT activity and airway obstruction. In a study by Casas et al (42), it was found that Slug was necessary for Twist to induce EMT, as the knockdown of Slug completely blocked the ability of Twist to inhibit E-cadherin transcription. Experiments in mice demonstrated that Slug was necessary for Twist to induce tumor cell invasion and metastasis. Furthermore, in human breast tumors, the expression of Twist and Slug was highly correlated. Thus, Twist and Slug were shown to work together to promote EMT and tumor metastasis (42). Although no significant correlation was observed between Twist and Slug in ESCC in the present study, a positive correlation was found for Twist and Snail expression, and Slug and Snail have a certain homology. These observations requires further research.

In conclusion, the present study found that Twist was highly expressed in ESCC and was associated with male sex. The expression of Slug was found to be associated with the degree of differentiation, TNM stage and vascular invasion in ESCC, and may have an inhibitory effect on the development of ESCC. Snail was found to be an independent prognostic factor in patients with ESCC, and the expression of Twist was positively correlated with the expression of Snail. Furthermore, the co-expression of Twist and Snail had a significant effect on the overall survival of patients with ESCC, suggesting that the inhibition of Twist and Snail expression simultaneously may be conducive to prolonging the overall survival of ESCC patients. These results provide a theoretical basis for the identification of a new therapeutic target for ESCC. The present study has certain limitations. It only preliminarily confirmed the roles of Twist, Slug and Snail in ESCC and their influence on prognosis. The mechanisms of the proteins cannot be identified by the statistical analysis of the immunohistochemistry and RT-qPCR results. In addition, the RT-qPCR results showed that the mRNA expression level of Slug in ESCC was lower than that in normal esophageal mucosa. However, the expression of slug in ESCC was higher than that in normal esophageal mucosa in the immunohistochemical experiment. In-depth studies combining experiments with tissues, cells and animal models are required to reveal the underlying mechanisms.

\section{Acknowledgements}

Not applicable.

\section{Funding}

The present study was supported by the National Natural Science Foundation of China (grant no. 81860422) and the graduate innovation and entrepreneurship start-up fund of Xinjiang Medical University (grant no. CXCY2018024).

\section{Availability of data and materials}

The datasets used and/or analyzed during the current study are available from the corresponding author on reasonable request.

\section{Authors' contributions}

SX and YZ designed and performed the experiments, analyzed the data and were the main contributors to the manuscript. HB and $\mathrm{HW}$ performed the experiments and interpreted data. CL and WZ were involved in the experiments and data collection. YM designed the experimental program. All authors read and approved the final manuscript.

\section{Ethics approval and consent to participate}

The study was approved by the Medical Ethics Committee of the First Affiliated Hospital of Xinjiang Medical University (approval no. 20180223-08). Written informed consent was obtained from all participants.

\section{Patient consent for publication}

Not applicable.

\section{Competing interests}

The authors declare that they have no competing interests.

\section{References}

1. Bray F, Ferlay J, Soerjomataram I, Siegel RL, Torre LA and Jema A: Global cancer statistics 2018: GLOBOCAN estimates of incidence and mortality worldwide for 36 cancers in 185 countries. CA Cancer J Clin 68: 394-424, 2018.

2. Chen R, Zheng RS, Zhang SW Zeng HM, Wang SM, Sun KX, Gu XY, Wei WW and He J: Analysis of incidence and mortality of esophageal cancer in China, 2015. Zhonghua Yu Fang Yi Xue Za Zhi 53: 1094-1097, 2019 (In Chinese).

3. Napier KJ, Scheerer M and Misra S: Esophageal cancer: A review of epidemiology, pathogenesis, staging workup and treatment modalities. World J Gastrointest Oncol 6: 112-120, 2014.

4. Zheng S, Vuitton L, Sheyhidin I, Vuitton DA, Zhang Y and Lu X: Northwestern China: A place to learn more on oesophageal cancer. Part two: Gene alterations and polymorphisms. Eur J Gastroenterol Hepatol 23: 1087-1099, 2011.

5. Qing L, Liang M, Liu T, Vuitton L, Zheng S, Gao X, Lu M, Li X, Sheyhidin I and Lu X: M2 isoform of pyruvate kinase (PKM2) is upregulated in Kazakh's ESCC and promotes proliferation and migration of ESCC cells. Tumour Biol 37: 2665-2672, 2016.

6. Pang L, Li Q, Wei C, Zou H, Li S, Cao W, He J, Zhou Y, Ju X, Lan J, et al: TGF- $\beta 1 /$ Smad signaling pathway regulates epithelial-to-mesenchymal transition in esophageal squamous cell carcinoma: In vitro and clinical analyses of cell lines and nomadic Kazakh patients from northwest Xinjiang, China. PLoS One 9: e112300, 2014.

7. de la Iglesia JE, de la Calle MA, pérez GC, Pérez RR and Delgado AA: Esophageal cancer: Anatomic, particularities, staging, and, imaging techniques. Radiologia 58: 352-365, 2016.

8. Liu B, Bo Y, Wang K, Liu Y, Tang X, Zhao Y, Zhao E and Yuan L: Concurrent neoadjuvant chemoradiotherapy could improve survival outcomes for patients with esophageal cancer: A metaanalysis based on random clinical trials. Oncotarget 21: 20410-20417, 2017 
9. Huang Y, Wang H, Luo G, Zhang Y, Wang L and Li K: A systematic review and network meta-analysis of neoadjuvant therapy combined with surgery for patients with resectable esophageal squamous cell carcinoma. Int J Surg 38: 41-47, 2017

10. Hu Y, Li Z, Mi DM, Cao N, Zu SW, Wen ZZ, Yu XL and $\mathrm{Qu}$ Y: Chemoradiation combined with regional hyperthermia for advanced oesophageal cancer: A systematic review and meta-analysis. J Clin Pharm Ther 42: 155-164, 2017.

11. Parvani JG and Schiemann WP: Sox4, EMT programs, and the metastatic progression of breast cancers: Mastering the masters of EMT. Breast Cancer Res 15: R72, 2013.

12. Bruner HC and Derksen WB: Loss of E-cadherin-dependent cell-cell adhesion and the development and progression of cancer. Cold Spring Herb Perspect Biol 1: 10, 2018.

13. Siar $\mathrm{CH}$ and $\mathrm{Ng} \mathrm{KH}$ : Differential expression of transcription factors snail, slug, SIP1, and twist in ameloblastoma. J Oral Pathol Med 43: 45-52, 2014.

14. Qian Q, Young X, Tao H, Qin $\mathrm{C}$ and $\mathrm{Xu} \mathrm{J}$ : Normal and disease-related biological functions of Twist1 and underlying molecular mechanisms. Cell Res 22: 90-106, 2012.

15. Yu L, Mu Y, Sa N, Wang $\mathrm{H}$ and Xu W: Tumor necrosis factor $\mathrm{o}$ induces epithelial-mesenchymal transition and promotes metastasis via NF- $\mathrm{KB}$ signaling pathway-mediated twist expression in hypopharyngeal cancer. Oncol Rep 31: 321-327, 2014.

16. Yang $\mathrm{J}$ and Weinberg RA: Epithelial-mesenchymal transition: At the crossroads of development and tumor metastasis. Dev Cell 14: 818-829, 2008.

17. Cao J, Wang X, Dai T, Wu Y, Zhang M, Cao R, Zhang R, Wang G, Jiang R, Zhou BP, et al: Twist promotes tumor metastasis in basal-like breast cancer by transcriptionally upregulating ROR 1 . Theranostics 8: 2739-2751, 2018.

18. Wang Y, Shi L, Li J, Wang H and Yang H: Involvement of twist in NNK exposure-promoted lung cancer cell migration and invasion. Toxicol In Vitro 63: 104740, 2019.

19. Lyu P, Zhang SD, Yuen HF, McCrudden CM, Wen Q, Chan KW and Kwok HF: Identification of Twist-interacting genes in prostate cancer. Sci China Life Sci 60: 386-396, 2017.

20. Hajra KM, Chen DY and Fearon ER: The slug zinc-finger protein represses E-cadherin in breast cancer. Cancer Res 62: 1613-1618, 2002.

21. de Souza Palma C, Grassi ML, Thomé CH, Ferreira GA, Albuquerque D, Pinto MT, Melo FU, Kashima S, Covas DT, Pitteri SJ and Faça VM: Proteomic analysis of epithelial to mesenchymal transition (EMT) reveals cross-talk between snail and HDAC1 proteins in breast cancer cells. Mol Cell Proteomics 15: 906-917, 2016.

22. Wang Y, Shi J, Chai K, Ying X and Zhou BP: The role of snail in EMT and tumorigenesis. Curr Cancer Drug Targets 13: 963-972, 2013.

23. Kaufhold S and Bonavida B: Central role of snaill in the regulation of EMT and resistance in cancer: A target for therapeutic intervention. J Exp Clin Cancer Res 33: 62, 2014.

24. Phillips S and Kuperwasser C: SLUG: Critical regulator of epithelial cell identity in breast development and cancer. Cell Adh Migr 8: 578-587, 2014.

25. Alves CC, Carneiro F, Hoefler H and Becker KF: Role of the epithelial-mesenchymal transition regulator Slug in primary human cancers. Front Biosci (Landmark ED) 14: 3035-3050, 2009.

26. Livak KJ and Schmittgen TD: Analysis of relative gene expression data using real-time quantitative PCR and the 2(-Delta Delta C(T)) method. Methods 25: 402-408, 2001

27. Zheng S, Vuitton L, Sheyhidin I, Vuitton DA, Zhang Y and Lu X: Northwestern China: A place to learn more on oesophageal cancer. Part one: Behavioural and environmental risk factors. Eur J Gastroenterol Hepatol 22: 917-925, 2010
28. Qiao W, Jia Z, Liu H, Liu Q, Zhang T, Guo W, Li P, Deng M and $\mathrm{Li}$ S: Prognostic and clinicopathological value of twist expression in breast cancer: A meta-analysis. PLoS One 12: e0186191, 2017.

29. Gong T, Xue Z, Tang S, Zheng X, Xu G, Gao L, Zhao G, Hong L, Tang G, Zhang H, et al: Nuclear expression of twist promotes lymphatic metastasis in esophageal squamous cell carcinoma. Cancer Biol Ther 13: 606-613, 2012.

30. Shih JY and Yang PC: The EMT regulator slug and lung carcinogenesis. Carcinogenesis 32: 1299-1304, 2011.

31. Cho YA, Kim EK, Cho BC, Koh YW and Yoon SO: Twist and snail/slug expression in oropharyngeal squamous cell carcinoma in correlation with lymph node metastasis. Anticancer Res 39: 6307-6316, 2019

32. Hasan MR, Sharma R, Saraya A, Chattopadhyay TK, DattaGupta S, Walfish PG, Chauhan SC and Ralhan R: Slug is a predictor of poor prognosis in esophageal squamous cell carcinoma patients. PLoS One 8: e82846, 2013.

33. Cui N, Yang WT and Zheng PS: Slug inhibits the proliferation and tumor formation of human cervical cancer cells by up-regulating the $\mathrm{p} 21 / \mathrm{p} 27$ proteins and down-regulating the activity of the wnt $/ \beta$-catenin signaling pathway via the trans-suppression akt1/p-akt1 expression. Oncotarget 7: 26152-26167, 2016.

34. Sun $X$ and Liu Y: Activation of the wnt $/ \beta$-catenin signaling pathway may contribute to cervical cancer pathogenesis via upregulation of twist. Oncol Lett 14: 4841-4844, 2017.

35. Salehi S, Mansoori B, Mohammadi A, Davoudian S, Shenas SM, Shajari N, Majidi J and Baradaran B: An analysis of suppressing migratory effect on human urinary bladder cancer cell line by silencing of snail-1. Biomed Pharmacother 96: 545-550, 2017.

36. Shenas SM, Mansoori B, Mohammadi A, Salehi S, Kaffash B, Talebi B, Babaloo Z, Shanehbandi D and Baradaran B: SiRNA-Mediated silencing of snail-1 induces apoptosis and alters micro RNA expression in human urinary bladder cancer cell line. Artif Cells Nanomed Biotechnol 45: 969-974, 2017.

37. Chang HY, Tseng YK, Chen YC, Shu CW, Lin MI, Liou HH, Fu TY, Lin YC, Ger LP, Yeh MH and Liu PF: High snail expression predicts a poor prognosis in breast invasive ductal carcinoma patients with HER2/EGFR-positive subtypes. Surg Oncol 27: 314-320, 2018.

38. Smit MA, Geiger TR, Song JY, Gitelman I and Peeper DS: A twist-snail axis critical for TrkB-induced epithelial-mesenchymal transition-like transformation, anoikis resistance, and metastasis. Mol Cell Biol 29: 3722-3737, 2009.

39. Dave N, Guaita-Esteruelas S, Gutarra S, Frias A, Beltran M, Peiró $\mathrm{S}$ and de Herreros AG: Functional cooperation between snail1 and twist in the regulation of ZEB1 expression during epithelial to mesenchymal transition. J Biol Chem 286: 12024-12032, 2011.

40. Oh KY, Yoon HJ, Lee JI, Ahn SH and Hong SD: Twist and snail expression in tumor and stromal cells of epithelial odontogenic tumors. J Oral Pathol Med 46: 127-133, 2017.

41. Mahmood MQ, Walters EH, Shukla SD, Weston S, Muller HK, Ward C and Sohal SS: $\beta$-Catenin, twist and snail: Transcriptional regulation of EMT in smokers and COPD, and relation to airflow obstruction. Sci Rep 7: 10832, 2017.

42. Casas E, Kim J, Bendesky A, Ohno-Machado L, Wolfe CJ and Yang J: Snail2 is an essential mediator of twist1-induced epithelial mesenchymal transition and metastasis. Cancer Res 71: 245-254, 2011

This work is licensed under a Creative Commons Attribution-NonCommercial-NoDerivatives 4.0 International (CC BY-NC-ND 4.0) License. 